\title{
Western Sydney is Hot! \\ Community arts and changing perceptions of the West
}

\section{Christina Ho}

University of Technology, Sydney

Gateways: International Journal of Community Research and Engagement Vol 5 (2012): 35-55

(C) UTSePress and the author

ISSN 1836-3393
Fibro houses, suburban sprawl, crime, bogans. Traditionally, Sydney's western suburbs have been associated with all the markers of poverty and disadvantage, and a distinct lack of cultural sophistication. To be a 'Westie' was to embrace a working-class culture of plain talking, manual labour and a general suspicion of art, higher education and other 'pointyheaded' pursuits. More recently, as Western Sydney has become increasingly multicultural, the stereotypes have focused more on 'ethnic crime' and immigrant 'ghettoes'.

However, these negative images of Western Sydney are starting to shift, pushed along particularly by attempts to boost cultural and artistic activity in the region. In the last decade or so, Western Sydney has seen a proliferation of new cultural and artistic institutions, organisations and community initiatives, and advocates now hail the region as Australia's newest cultural sensation. To what extent have these positive images of cultural vibrancy displaced the older negative ones? What role have community arts played in this re-imagining of Western Sydney?

This article examines these questions through a framework of evaluating social impacts. While evaluation of arts programs typically focus on their outputs and outcomes and on individual participants, I have attempted to push out the parameters of evaluation to explore social impacts, in particular, the impact of arts programs on the broader social perceptions of a region. In doing so, I have also sought to expand the methods available for undertaking evaluation and challenge the prevailing preoccupation with measurement, arguing that quantitative measures narrow the scope of what can be recognised within the wide range of impacts that arts programs can have.

\section{EVALUATION OF SOCIAL IMPACT: GETTING BEYOND MEASURING OUTPUTS}

In the last 25 years or so, evaluation has become the new mantra of funding bodies, community organisations, and it seems, any organisation providing any kind of service. Increasingly, organisations are becoming eager to demonstrate the impact 
of their work and to improve their organisational performance, partly in response to requirements by their funders for greater accountability.

This trend has given rise to numerous evaluation models, mostly relying on quantitative methods. These include costbenefit analysis, social return on investment, social accounting and audit and results-based accountability, to name a few (Productivity Commission 2010, p. 51). Most of these approaches devise indicators for measuring the outputs and outcomes of an organisation or program, often attempting to translate these contributions into financial values. However, critics see these frameworks as too narrow to capture the full spectrum of the contributions which are actually being made.

This has been particularly evident in the arts. Cultural policy decisions can no longer refer to notions of 'excellence', 'quality' or 'artistic value' (Belfiore 2004, p. 188), but rather must show, in the form of 'hard evidence', exactly what individual or social benefits are generated by programs. However, in many ways, the impacts of arts programs are inherently difficult to measure. They occur in complex, open systems where it is difficult to determine which actions led to particular outcomes. They are often about providing intangible as well as tangible benefits, focusing on the processes of participation and creation rather than exclusively on the end-product. They are often about changing perceptions and attitudes, not just of participants but of a broader audience. While their impact may be felt immediately, arts projects often generate ripple effects that continue long after the life of the project.

This article focuses on these longer-term ripple effects, and in particular, the impact of community arts programs on perceptions of Western Sydney. In focusing on this level of impact, I deliberately targeted an area that is difficult to evaluate. As mentioned earlier, evaluation commonly focuses on outputs or the 'direct products of the organisation's activities', such as number of classes taught, number of hours of service delivered, numbers of participants served (Productivity Commission 2010, p. 35). However, evaluations can also consider outcomes, or the 'intended benefits for participants during and after an organisation's activities' (Productivity Commission 2010, p. 35), including new knowledge and skills, changed attitudes or values and modified behaviour. These outcomes are obviously broader than simply accounting for what services were delivered.

However, fewer evaluations consider broader impacts or the longer-term benefits for the individual and the community, including 'feedback effects' and 'spillovers' from activities (Productivity Commission 2010, p. 44). These include improved community participation, stronger communities and enhanced local identity. There is less data available to assess such impacts, 
and as noted above, it can be difficult to isolate the contribution of any one program, especially when goals may not be fully realised for some time or when significant unanticipated results emerge.

In Australia the study of the social impact of the arts is gradually developing, although from a slow start, thanks to the work of Deirdre Williams, who in the mid 1990s pioneered a methodology later taken up by numerous international studies. Commissioned by the Australia Council for the Arts to examine the long-term value of 89 community-based arts projects, Williams found evidence of many social, educational, economic and artistic benefits. She highlighted a critical link between community culture and social cohesion, demonstrating how 'community-based arts programs are powerful catalysts for developing healthy, viable communities' (Williams 1996). In particular, community-based art programs can create a sense of place, affirm the values of the community, assert its differences and communicate its aspirations (Williams 1996). Subsequent studies have found similar benefits (Matarasso 1997; Walker, Fleming \& Sherwood 2003; Ramsey White \& Rentschler 2005).

Particularly pertinent to this article, Guetzkow (2002) has assessed the impact of the presence of artists, arts organisations and public art, finding that this can improve the image and status of the community, promote neighbourhood cultural diversity and reduce crime (p. 3). These factors may all strengthen an area's 'cultural vitality', or a community's capacity for creating and supporting creative expression on its own terms (Opdycke et al. 2003, p. 8). As Hawkes (2001) has argued, cultural vitality should be considered the 'fourth pillar of sustainability', which is just as important in a community as the other dimensions of economic viability, social equity and environmental sustainability. The Melbourne-based Cultural Development Network has now devised a framework for arts indicators, which includes the creation, dissemination, validation and support of arts and culture as a means of measuring a local community's cultural vitality (CDN 2010, p. 1).

\section{THE SOCIAL IMPACT OF COMMUNITY ARTS PROGRAMS IN WESTERN SYDNEY: A CASE STUDY}

\section{The Information and Cultural Exchange (ICE)}

While Western Sydney has been the focus of much social research (Burchell 2003; Butcher 2003; Collins \& Poynting 2000), few studies have focused specifically on the social impact of community arts programs on the region. This article aims to redress this gap, documenting changing perceptions of the West's cultural vitality based on a case study of the community organisation, Information and Cultural Exchange (ICE). ICE works at 'the intersection of arts, community and technology' (ICE 2011), specialising in digital media and community cultural development through the use of digital stories, film and urban music. For more than 20 years, ICE programs have provided training, mentoring, 
networking opportunities and professional development, building the career foundations of some highly successful Australian artists, particularly in film-making and hip hop.

Located in the Western Sydney suburb of Parramatta, ICE has been a pioneer in delivering services to a region traditionally neglected by arts bodies, working mainly with young people from migrant and refugee backgrounds. Its best-known programs include:

-Artfiles: an artists' professional development program that includes a directory of more than 2000 artists living or working in Western Sydney, the most comprehensive database of its kind

-Urban cultures: hip hop production and performance projects, providing skill development, mentoring and career information for aspiring artists

-Screen culture: ICE's film-making program which includes film festivals, digital storytelling, professional mentoring and competitions

- Switch Digital Arts Centre: home to ICE's training programs, facilities and equipment services.

ICE is one of Australia's most successful community arts organisations. In 2007, it was recognised by the Australia Council for the Arts as one of its eleven 'Key Producers' comprising 'leading Australian community arts and cultural development organisations', who receive long-term funding (Australia Council 2009 , p. 3). As a relatively mature community organisation whose impact clearly exceeds what can be captured by basic project evaluations, ICE provides an ideal case study for exploring the social impact of arts projects. In particular, I aim to uncover ICE's role in the changing image of Western Sydney.

A case study approach is useful as it allows an in-depth exploration of the experiences of one organisation, while firmly locating that exploration within a broader social context. Consideration of these two dimensions is vital in investigating the impact of particular cultural interventions on the wider environment, in this case Western Sydney. In more practical terms, as Yin (1989, p. 20) notes, the case study's 'unique strength' is its 'ability to deal with a full variety of evidence', including documents, artefacts, interviews and observations. This study incorporates findings based on multiple research methods, including surveys, interviews, and media analyses, all focused on the role of ICE within its wider Western Sydney setting.

This research is part of a larger project, 'Ripple effects: community building, participation and cultural citizenship through creative practices in Western Sydney'. The project was funded by the Australian Research Council, and conducted in partnership between the University of Technology, Sydney, Information and Cultural Exchange and the Australia Council for the Arts and Arts NSW. 


\section{SYDNEY'S HARLEM? WESTERN SYDNEY'S NEW GROOVE}

Research on the social impact of the arts invariably highlights the importance of community-building and local identity and image. This is particularly important for historically under-resourced areas such as Western Sydney. A vast region, home to nearly 2 million people covering 14 local government areas (OWS 2011), Western Sydney is often regarded as the 'other Sydney' (Collins \& Poynting 2000), a poor cousin of the rest of the city. The region has traditionally been a working class heartland, home to much of the city's manufacturing and industrial employment, and the destination of the majority of new migrants to Sydney. The western suburbs continue to suffer from higher rates of poverty, unemployment and other indicators of disadvantage relative to the rest of Sydney, and have also been perceived as a cultural wasteland, an endless, 'culture-less' suburban sprawl.

However, Western Sydney arts advocates assert that the region is in fact a dynamic and creative place bursting with stories about contemporary multicultural Australia. ICE Director, Lena Nahlous, compares Western Sydney with areas like New York's Harlem and the Bronx and London's Brixton, saying that people will increasingly want to come to Western Sydney because it, too, is 'edgy', 'vibrant' and 'authentic' (Nahlous 2011).

Indeed Western Sydney appears to be experiencing a cultural renaissance. While previously, the West tended to look towards the CBD for its cultural consumption, this 'centreperiphery' perception is no longer so dominant (NSW Ministry for the Arts 2006, p. 7). State cultural institutions and festivals such as the Sydney Festival, and the Sydney Writers Festival are increasingly travelling west, along with numerous other major events that were previously the exclusive preserve of the city.

Moreover, local cultural production is increasingly gaining recognition. A 2006 State Government report on the arts in Western Sydney noted that there has been 'increased recognition of the region and its unique cultural values and expression' (NSW Ministry for the Arts 2006, p. 5). In particular, it stated that 'Western Sydney has become an incubator for innovative strategies', including in arts practice. 'Cutting edge, hybrid and innovative artistic and cultural practice has featured across a range of art forms, and "community cultural development" has been reinvented in 21st century terms' (NSW Ministry for the Arts 2006, p. 6).

For example, according to Councillor Chiang Lim, Parramatta now markets itself as the 'creative city', a new arts hub that demonstrates that 'culture and art are not the exclusive domain of inner Sydney' (Pitt 2010). A recent article in the Sydney Morning Herald, 'The zest in the west: Sydney's sizzling centre', notes that Parramatta has 'positioned itself as a new dining and arts hub, especially for the under-25 set' (Pitt 2010). Western Sydney has even received grudging recognition from establishment 
Table 1: Stories published in the Parramatta Advertiser, 2002 and 2010
Table 2: Stories published in the Sydney Morning Herald, 2002 and 2010 art critics. For example, in his review of the 2005 multi-sited exhibition Western Front: Contemporary Art from Western Sydney, the Sydney Morning Herald's John McDonald wrote:

... things are starting to look a lot brighter in the western suburbs. Once upon a time there was nothing but concrete shopping malls to charm the visitor. The bricks and grime of these suburban sargassos were the legacy of councillors who resembled Bill Heslop from Muriel's Wedding, with his slogan, 'You Can't Stop Progress!' Nowadays there is at least a tacit acknowledgement that culture has a place at the table, alongside commerce. There is also a recognition that communities without adequate cultural facilities are breeding grounds for boredom, vandalism, social misery and crime (McDonald 2005, p. 28).

The growth of arts activities and public investment in the arts is reflected by a parallel growth in coverage of the arts by local media. The Parramatta Advertiser has a circulation of nearly 83000 , and is delivered to households in 33 suburbs in the Parramatta area (Parramatta Advertiser 2011). A comparison of its coverage of the arts in two years - 2002 and 2010 - revealed that articles on the arts in the local area more than doubled, from a total of 70 items in 2002 to 160 in 2010 (see Table 1). There was also a degree of diversification in the type of arts stories covered. While in 2002 26 per cent of arts stories covered art exhibitions, in 2010, this had halved to just 13 per cent. In 2010, art classes and festivals (such as the inaugural Parramasala South Asian cultural festival) featured more prominently.

\begin{tabular}{lll}
\hline & $\mathbf{2 0 0 2}$ & $\mathbf{2 0 1 0}$ \\
\hline Total number of stories & 70 & 160 \\
\hline Top themes of stories: & & \\
\hline -Art exhibitions & $26 \%$ & $13 \%$ \\
\hline -Art classes & $13 \%$ & $24 \%$ \\
\hline -Festivals & $4 \%$ & $18 \%$ \\
\hline -Performance & $19 \%$ & $15 \%$ \\
\hline - Local artist achievements & $7 \%$ & $11 \%$ \\
\hline
\end{tabular}

A similar trend was evident, although on a much smaller scale, in Sydney's broadsheet newspaper, the Sydney Morning Herald. Searching for stories on Western Sydney, Parramatta, art and culture, I identified four articles in 2002 (see Table 2). The eight listings related to events included in 'what's on' columns.

\begin{tabular}{lll}
\hline & $\mathbf{2 0 0 2}$ & $\mathbf{2 0 1 0}$ \\
\hline Stories & 4 & 8 \\
\hline Listings & 8 & 8 \\
\hline
\end{tabular}

In 2010, the number of stories had doubled to eight, including one on ICE's Arab Film Festival but the number of listings was unchanged. These stories obviously do not represent the full range of reporting on Western Sydney as a whole in the 
newspaper. However, these small numbers provide an indication of the continuing marginality of Western Sydney arts and culture. Visibility is improving, but from a very low base.

This raises the question of whether changes occurring in Western Sydney are affecting the broader arts and culture hierarchies. To some extent, it is very much a local phenomenon which is not radically transforming external perceptions. However, the growth of local capacity and energy is certainly being seized upon by Western Sydney-based practitioners.

As part of this study, we conducted in-depth interviews with 18 community arts workers based in Western Sydney. All discussed the transformation of the Western Sydney arts scene, often enthusiastically pointing out examples of the proliferation of arts initiatives, from theatre and film-making to hip hop and digital storytelling. In the words of theatre worker, Lina Kastoumis:

we're young and funky. It's a funky constituency, all the artists coming through, and it's only going to get better ... No one's even yet touched an iota of what's going to come out. I see a boom period in five years of more filmmakers, more sound artists, more digital artists coming out (Kastoumis 2010).

According to veteran community arts worker, Alissar Chidiac, Western Sydney artists no longer need to rely on citybased arts resources:

Gone are the days where you had to get someone from Metro in Paddington, who was inevitably blonde and going to talk about how they've never - and I'm not exaggerating - they never go past Glebe, you know? ... I mean, that's where you used to get your new media kind of support. Metro screen! Metro screen! Paddington was the only thing! (Chidiac 2010).

The result has been a transformation among Western Sydney cultural producers' perceptions of the region. No longer is it a place to 'escape', as filmmaker and arts worker, Maria Tran, puts it:

... especially for me, coming from Western Sydney, I feel very connected here because prior to [being involved with ICE], I was with everyone else, thinking, 'Yeah, this place is a ghetto. I want to get out of this place'. But now I'm learning more about the people who live in this area, and seeing the different projects that are happening. It is quite amazing... Yeah. I feel proud of being in this region! (Tran 2011).

How has this transformation occurred? In answering this question it's important to consider the crucial role played by governments in building the arts infrastructure in the region.

\section{BUILDING THE ARTS INFRASTRUCTURE IN WESTERN SYDNEY}

At a macro level, Western Sydney's cultural renaissance reflects major public investment in arts infrastructure in the region, facilitated through the NSW Government's Western Sydney 
Arts Strategy, launched in 1999. The aims of the strategy were to 'encourage greater participation in the arts by the people of Western Sydney, increase business support, assist job creation, highlight existing infrastructure and resources, and make recommendations for specific initiatives' (NSW Ministry for the Arts \& NSW Government's Office of Western Sydney 1999, p. 1).

Prior to this time, Penrith hosted the only regional gallery in Western Sydney (NSW Ministry for the Arts \& NSW Government's Office of Western Sydney 1999, p. 9). By the mid 2000s, the state government had funded the establishment or enhancement of nearly 10 major arts centres in Western Sydney, including centres in Blacktown, Casula, Parramatta, Penrith, Fairfield and Hawkesbury (NSW Ministry for the Arts 2006). Although most of these institutions were established by local governments, state government funding 'enabled these organisations to grow beyond a local provider role' (NSW Ministry for the Arts 2006, p. 5). Acting together, each has encouraged local cultural production and participation in the arts, heightening cultural vibrancy in Western Sydney.

The Arts Strategy also mobilised local councils to invest in the arts, providing dollar for dollar matched funding for investments in the development and promotion of the arts (NSW Ministry for the Arts 2006, p. 9). As a result, it is now standard for local councils to develop annual cultural plans and employ cultural development officers.

The 2000 Sydney Olympics was another milestone, with the creation of Sydney Olympic Park in Homebush adding a major cultural asset to Sydney's west. At the time of the opening of Stadium Australia, a Daily Telegraph story proclaimed: 'Sydney is shifting on its axis. Today its focus is beginning a slow, definite and logical drift towards the west ...' (Lalor 1999, p. 44). Similarly, the Sydney Morning Herald reported that 'Suddenly, and for the first time, a significant part of Sydney's sporting and cultural focus has shifted westwards' (Dennis 1999, p. 11).

Western Sydney has also attracted substantial funding for Community Cultural Development (CCD) work (previously known as Community Arts). In 2004, out of all the funding provided by the Australia Council to Western Sydney organisations and individuals, nearly half (47 per cent) went to CCD projects (Lally 2004 , p. 13). Some organisations, like ICE, have particularly benefited from this policy focus on Western Sydney, attracting increased levels of funding and recognition.

Brown (2008, p. 228) argues that CCD processes produce knowledge about social issues, and can also 'allow powerful transformations of the way social ... problems are framed, [and] of the way solutions are sought ...' Over the last decade or so, CCD projects have been crucial in forging a particular Western Sydney model of cultural expression, and ICE has been at the forefront of this movement. 


\section{ICE'S ROLE IN DEVELOPING THE ARTS IN WESTERN SYDNEY}

Because ICE's period of growth coincided with the rollout of the Western Sydney Arts Strategy, and because the organisation often works in partnership with others, it is impossible to pinpoint the precise role played by ICE in the evolution of the arts scene in Western Sydney. The question of attribution is always vexed when it comes to social impacts arising from complex environments where individuals and organisations are highly intertwined, and goals may not be fully realised for many years after the work is completed. The 'mediating environment', which includes economic conditions and social and demographic trends, is widely recognised as complicating attempts at evaluation (Productivity Commission 2010, p. 35).

Considering the relationship between the activities of community-based organisations and broader social outcomes, the Productivity Commission (2010, p. 43) classifies the contributions of organisations as either:

- sufficient for the outcome to arise

-necessary but alone not sufficient

-enhancing where the quality or extent of the outcome is greater relative to what otherwise would have happened.

While ICE programs may often be sufficient to achieve outcomes at the level of individuals, at the level of social impact they undoubtedly play an 'enhancing' role. No one organisation can claim responsibility for changing social perceptions and enhancing local identity. Even if governments can claim to have provided a large portion of the funding for arts infrastructure, it is grassroots organisations such as ICE that translate this funding into actual programs.

For example, ICE Director Lena Nahlous, describes the brokering role the organisation often plays in bringing artists into the region for collaborations. She recounts well-known artists touring in Sydney, such as DJ Pogo, Sarah Love or The Herd, who worked with ICE to 'connect with emerging artists'. Nahlous also describes how ICE increasingly receives calls from casting agencies and other organisations wanting to employ people from specific cultural backgrounds, recalling examples of ICE working with young actors preparing for roles on national television programs (Nahlous 2011).

As part of this research, we conducted a survey in 2009-2010 to gauge recognition of ICE programs among 50 mainstream Western Sydney institutions, such as councils, educational institutions, and local media. We asked respondents what impacts they thought ICE projects had. Many credited ICE with playing a key role in the Western Sydney arts transformation, saying the organisation:

—'helps create identity in Western Sydney'

- 'contributed significantly to a change of identity and perception of the area' 
— 'brought a lot of interest in Western Sydney from the outside'

- 'built an arts precinct in Parramatta'.

In our in-depth interviews with community arts workers, this comment, from community theatre worker, Claudia Chidiac, was typical:

I think there's a handful of organisations in Western Sydney ... that have made people want to be here, have made people want to work in the region, and ICE have really led the way in turning Western Sydney into [something] really sexy... people were seeing all the work that was coming out of this region, and it was always leading back to ICE (Chidiac 2010).

While there was much positive recognition of ICE among our survey respondents, a minority viewed ICE's visibility in a negative manner. The following comments were common among this group:

- 'they are a good PR machine'

- 'there is a lot of PR and hype'

- 'very good at promoting and documenting their work'.

One respondent stated, 'I'm not sure about the substance behind the gloss', while another compared ICE to a 'show pony' that was attractive to investors. For these respondents, the practical contribution of ICE was difficult to distinguish from all the promotional material. Some argued ICE had drifted away from traditional community work, embracing a more commercialised approach that required greater investment in self-promotion and branding.

ICE is well recognised for its slick, professional marketing and promotion. This has been an important ingredient in its mission to bring visibility to Western Sydney cultural activity. Particularly in the last decade, the organisation has had a consistent brand aesthetic, one that connotes hip, tech savvy youth and cutting-edge urban cultures. From the organisation's massive website to its annual reports, weekly newsletters and flyers for projects, all ICE materials are professionally produced, artistically designed, and singularly upbeat in their written and visual communication. In many ways ICE provides a textbook study in how professional marketing has enabled a relatively small organisation to 'punch above its weight', securing visibility in a crowded landscape.

While this has raised concerns about whether ICE's focus on promotion comes at the cost of its traditional communitybased work, ultimately, building visibility for the ICE brand has also meant greater visibility for Western Sydney arts in general. This has given rise to other criticisms that ICE has become so synonymous with Western Sydney arts that it has monopolised the field, leaving little room for other players. ICE attracts a large share of public funding going to Western Sydney, because according to community arts worker Tim Carroll, 'it's like a box has been ticked universally for Western Sydney, and that this one organisation ticks all those boxes for the funding bodies' (Carroll 
2010). Fellow community arts worker, Alissar Chidiac, notes that ICE has become 'shorthand language' for all community cultural activity in Western Sydney (Chidiac 2010).

It should be noted that like any organisation, the fact that ICE attracts its fair share of critics is simply due to the competitive nature of the sector in which it is located. Ultimately, though, it would be unfair to claim that there was no 'substance' behind the 'hype' at ICE. In some ways ICE is a victim of its own self-promotion, excessively elevating expectations of what the organisation can achieve, inevitably leading to some disappointment. We now turn to details of some of the 'substance' of ICE's CCD work which, I argue, has made a solid social impact.

\section{COMMUNITY ARTS FOR THE 21ST CENTURY: THE ICE MODEL}

It is impossible to definitively demonstrate the impact of one organisation's work on the shifting perceptions of an entire region. However, key features of ICE's work align with what has been recognised as cutting-edge arts practice in Western Sydney. These include ICE's focus on:

- the creative possibilities of new media and technology

-young people from culturally diverse backgrounds.

Some of the new interest in Western Sydney cultural production stems from the innovative models of community cultural development (CCD) emerging from the region. This reflects the NSW Government's characterisation of the region, as noted above, as an 'incubator for innovative strategies' where 'community cultural development' has been 'reinvented in 21st century terms' (NSW Ministry for the Arts 2006, p. 6).

ICE is widely recognised as being at the forefront of this 'new CCD', particularly because of its emphasis on digital technology with digital arts training, urban music, digital storytelling and other screen arts featuring heavily in its programs. Challenging traditional notions of the digital divide, ICE has leapt into the new media era, providing access to traditionally technology-poor populations. According to theatre worker Lina Kastoumis, ICE was 'smart enough 10 or 15 years ago to jump on the fact that digital technologies were going to become widespread and accessible, so why not skill people up to use them?' (Kastoumis 2010).

Digital storytelling, arguably the fastest growing genre in CCD work, has been a particularly successful component of ICE's programming. Digital stories comprise short films, two to three minutes long, with a very simple format, usually a first person narrative told with images or simple animation, a voice-over and sometimes music. The simple format is deliberate, as it is intended to make digital storytelling an extremely accessible art form.

Widely used in community arts, education and even corporate communication (Couldry 2008, p. 387), digital storytelling represents something of a social movement, empowering 'ordinary people' to tell their stories, using simple, accessible technology. Couldry argues that 'digital storytelling 
contributes to a wider democratization of media resources and possibly to the conditions of democracy itself' (2008, p. 386). Burgess (2006, p. 206) describes digital storytelling in terms of 'vernacular creativity' - creative practices that emerge from nonelite social contexts and communicative conventions.

ICE participants have created a total of more than 200 digital stories, in projects such as:

—Digitales (global digital storytelling project)

-Vietnamese Story Exchange

- Penrith City Story Exchange

-Youth Digital Cultures

—Digi Diaries (Muslim Australian youth)

-Koori Story Exchange

-African Parenting Stories

-Yallah! What's your story? (Arab Australian youth)

-Bonds for Life; Life after Bonds (ex-Bonds workers).

An important goal of these projects is to provide skills to people in marginalised communities, who might not otherwise have access to the technology or expertise, in order to allow them to tell stories about themselves.

While basic in format, digital stories can be a powerful form of expression. Hartley and McWilliam (2009) suggest that the power of the digital story comes from its unique form, that 'combines the direct, emotional charge of confessional disclosure, the authenticity of the documentary, and the simple elegance of the format - it is a digital sonnet, or haiku' (p. 5). Similarly, Burgess (2006) explains that the personal narrative is the key feature of digital stories: 'Narrative accessibility, warmth, and presence are prioritized over formal experimentation or innovative "new" uses for technologies' (p. 207).

As a process, digital storytelling projects comprise a workshop lasting several days where participants learn how to use photo, sound and film-editing technology, and more importantly, engage in a 'story circle' process where they are encouraged to craft their own story in a group setting. Digital storytelling is clearly one of the more 'efficient' community arts programs, creating a finished product in a short period of time. This makes the art form popular among many organisations, including funders. For example, Kim Spinks, a senior arts bureaucrat in the NSW Government, enthused about the possibilities of digital storytelling:

When I'm explaining to other government agencies about what the arts can do, I often use projects like Digitales. They are a great example of [how] with good professional infrastructure and a professional arts organisation, you can get quite inexperienced people to make quite polished pieces of multimedia that have quite a personal charm to them (Spinks 2011).

Not only was digital storytelling 'empowering and artistically satisfying' for participants and audiences, Spinks explained, but for government agencies it was an example of a 
modest program that could deliver results. Moreover, the simple design of digital storytelling workshops allowed funders to easily understand the process involved, unlike some bigger, longer-term projects: 'With Digitales, you can see how it was done. You can see that not much was needed, besides a good facilitator, and some good infrastructure. It's accessible. It doesn't scare the horses' (Spinks 2011).

\section{YOUNG AND FUNKY: WESTERN SYDNEY AND CULTURAL DIVERSITY}

Apart from the emphasis on digital creativity, ICE has consistently promoted the vibrancy of Western Sydney's culturally diverse population, a strategy that aligns well with official government promotions. For example, Fairfield City Council's motto is 'Celebrating diversity', while in their official publicity, virtually all councils in Western Sydney describe their communities by referring to the number of different countries residents hail from. This is also typical of successive state governments' portraits of Western Sydney. For instance, the first paragraph in the 1999 document launching the Western Sydney Arts Strategy stated:

Western Sydney is one of the great cosmopolitan regions in Australia. Around 30 per cent of its people speak a language other than English at home; 60 per cent of Sydney's Aboriginal and Torres Strait Islander people reside there. It has a proud migrant and indigenous heritage (NSW Ministry for the Arts \& NSW Government's Office of Western Sydney 1999, p. i).

ICE also prominently frames its work in terms of cultural diversity. The first paragraph of its 2009 Annual Report states:

With over 100 nationalities calling it home, Greater Western Sydney is one of the most culturally diverse communities in the world. This complex region is currently exploding with stories, global influences, fresh interpretations and new collaborations. It's here that Australia's changing multicultural identity is being imagined and realised, and ICE is at the centre of this process (ICE 2009, p. 4).

In these representations, cultural diversity is valorised as a unique asset of Western Sydney, implicitly challenging two common stereotypes: on the one hand, traditional images of the West as a bland, suburban sea of fibro, and on the other hand, as an assemblage of ethnic ghettoes riddled with crime and deprivation.

Reflecting the shift away from the social deficit approach that characterised previous decades, community arts and development projects have reframed residents of Western Sydney. No longer disadvantaged and unsophisticated, they are now cultural producers with their own unique stories to tell. And many of these stories are about diversity, identity, cultural conflict, racism, hybridity and other themes relating to life in multicultural Australia. 
Elaine Lally argues that there is a new sense of confidence in Western Sydney, and the expression of a noticeable regional identity - one that is streetwise, reflecting a larrikin, battler instinct, not aiming to emulate what is done elsewhere (Lally 2010). Theatre worker Lina Kastoumis expresses in graphic terms the distinct approach taken in Western Sydney cultural production that reflects Australia's diversity:

... we look like real Australians, you know what I mean? It goes so counter to the Anglo-dominated representation you see on TV ... every time I watch Australian TV, especially commercial stations, I believe I'm living in a parallel universe. That's not the Australia I know ... So, when I go to an ICE event, or a Campbelltown event, or a Blacktown event, I'm at home in my diversity, and I'm a part of that diversity, and I feel very proud that there's a reality to us that we're rejoicing, celebrating, hanging shit on, but it's there, as opposed to the fallacy of the Anglo-centric world that we see on television (Kastoumis 2010).

The cultural productions Kastoumis refers to treat diversity as the norm, and Kastoumis herself speaks from the standpoint of a proud and assertive 'wog' as well as a professional arts worker. This kind of assertiveness, found throughout Western Sydney, has become increasingly common since the 1980s, when ethnic culture evolved from being something 'different and quaint' to something that could be edgy and political. Migrants could also be represented as 'excluded, suffering and angry' (Hawkins 1993, p. 140). However, migrants can now also express cultural pride in a contemporary way, without having to rely on traditional or folk representations. For example, ICE Director Lena Nahlous recounts a performance project featuring Chinese-Australian girls combining traditional fan dancing with hip hop (Nahlous 2011).

ICE is well known for its work with people from culturally diverse backgrounds, often in projects where cultural diversity and identity are the framing narratives. The post 9/11 climate has been hostile for many migrant communities, particularly Arab and Muslim Australians, who are geographically concentrated in Western Sydney. This follows earlier difficult periods for Vietnamese and other minority groups targeted by aggressive law and order politics that criminalised whole Western Sydney suburbs. In this environment, community arts programs play a vital role in telling alternative stories about multicultural Australia.

ICE programs deliberately target marginalised and vulnerable populations, including people from Arab, Pacific, African and Aboriginal backgrounds. The products of these projects often feature assertions of cultural pride, and speaking back to negative stereotypes. Some notable examples include:

-Of Middle Eastern Appearance (film by Paula Abood)

-Trouble Comes to Me (film by Shifa: Agents of Change, young Arab men)

-Media Places and Spaces (public art anti-racism project). 
Another important ICE initiative is the Arab Film Festival, which from small beginnings in Parramatta's Roxy Theatre in 2001, now tours nationally every year, boasting major public and private sponsorship and broad recognition among the Arab community in Australia.

In providing marginalised communities with a forum for self-expression, ICE programs realise in practical terms the official discourses valorising cultural diversity in Western Sydney. They provide tangible 'good news stories' about the success and dynamism of multiculturalism in Western Sydney, evidence that is readily taken up by local media, funding bodies and other institutions.

In 2006, the Australia Council's community partnerships scoping study stated that there was a need to 'find descriptive language to name and describe the arts and cultural activities in and with communities, so that this practice can be recognised as belonging to all people in communities and provide the potential for arts and cultural activities to assume a greater status in local communities' (2006, p. 8). I argue that organisations like ICE have begun to do just this, in creating a new language to describe the work of diverse communities. What might otherwise be viewed as idle amateur experimentation, or even a public nuisance (young people leaping across walls and fences in the practice of parkour), is transformed by organisations like ICE into authentic artistic expressions that reflect the vibrancy of multicultural Australian culture.

What is remarkable is that this alternative discourse has gained traction in an otherwise culturally conservative era. In some cases, such as ICE participant's Ali Kadhim's Parkour project, even senior government officials have accepted that their conventional definitions of what constitutes art might need to change. As the Australia Council's head of Community Partnerships, Frank Panucci, stated recently, Parkour (an urban movement art form combining climbing, leaping, rolling and balance to scale walls, fences and other urban obstacles), is now recognised as a legitimate art form for public funding - a shift that was unimaginable a few years ago (Panucci 2010). In 2010, the Australia Council and Qantas produced a short film featuring Kadhim, entitled Nine Lives, which was screened on Qantas domestic flights. Kadhim, a young man from Western Sydney whose family encouraged him to become a security guard after high school, now runs his own business providing Parkour workshops and making films of his exploits (Nahlous 2011).

In Western Sydney today, CCD projects are producing a wide range of cultural expressions that shift traditional stereotypes of the area as deprived and culture-less, as well as creating new ways of expressing cultural identity that valorise diversity. Of course, it is impossible to definitively measure the extent of these shifts in perception. Stories of a vibrant Western Sydney and positive images of ethnic minorities might gain most traction at a local level, their impact dissipating with distance. However, as noted above, several 
community arts worker interviewees stated emphatically that cultural producers and audiences were increasingly drawn to the area.

Perhaps the most powerful testament to the social recognition of Western Sydney's CCD work is the enormous success of ICE itself, which is certainly a new darling of the Australia Council and other public bodies. ICE works with some of the most stigmatised social groups in Australia today, including young Arab men, African refugees, Muslim Australian youth and Indigenous groups. It turns their public image on its head, representing these groups, and Western Sydney as a whole, as creative, dynamic and the true face of Australian multiculturalism. For this sort of work to be given the kind of recognition that ICE has received, is remarkable evidence of the ability of CCD work to shift powerful and ingrained social perceptions.

\section{CONCLUSION: HOW FAR HAS THE WEST COME?}

Despite the cultural renaissance of Western Sydney, however, little has been achieved in eradicating Sydney's overall arts and culture hierarchies. If the West is rising, it is from a very low base. As Alissar Chidiac says:

... but still people do put the eastern suburbs on a pedestal. I am not going to accept that yes, everyone's just really happy about how everything's growing and bursting in Western Sydney. I work with artists who, for them, still, it's second-rate for them to show in Western Sydney. They want to show their work in Paddington (Chidiac 2010).

Ironically, it may be the growth of CCD itself in Western Sydney that maintains such hierarchies. With CCD work snapping up a large portion of Australia Council funding for Western Sydney, there is much less scope for the development of visual arts, theatre, music or other more conventional art forms in the region. The Australia Council (2006, p. 7) admits that the CCD sector has at times 'been effectively marginalised from the broader arts and cultural industry' and that CCD has been regarded as too narrowly focusing on disadvantaged groups, producing outcomes regarded as inferior to other fields of cultural activity (Brook 2008, p. 189).

Elaine Lally (2010) puts it more bluntly, arguing that Western Sydney figures so highly in CCD funding because it is a way of marginalising the arts in Western Sydney. Policy makers might be happy to fund CCD in the region, she argues, but have been very negative about Western Sydney's capacity to generate what they consider to be 'real' art. Hawkins (1993) describes it this way: 'Community arts are located out on the cultural fringes where marginal groups produce marginal art' (p. xix).

It should be remembered that Western Sydney continues to experience higher levels of disadvantage compared to other areas of Sydney. In this sense, a 'developmental' approach to arts is perhaps more justified here than elsewhere. However, critics argue that the culture of CCD can limit artistic experimentation. 
Hawkins describes an 'aesthetics of affirmation' that has historically prevailed in the CCD sector. This approach seeks to produce affirmative images of 'the marginalised', privileging the self-esteem of the participants (p. 137). This can create a uniformity in cultural production: "A "good" community arts project is either harmlessly wholesome in its representation of unity, harmony and togetherness, or it is crudely rhetorical in its representations of us against them' (p. 163).

This is evident in the genre of digital storytelling. As discussed above, the power of these short films rests almost exclusively on the intimacy of the first-person narrative, and the authenticity of the storyteller as a real person recounting their thoughts and experiences. While the genre provides an accessible vehicle for cultural expression, the digital stories produced are often predictable and formulaic in their content, narrative style and plot development.

Similarly, McEwen characterises CCD as 'process rather than product' emphasising 'the making of community rather than the making of arts' (2008, pp. 42, 50. See also Mills 2008, p. 207). As Rose (1997) puts it, the significance of CCD lies in participation, rather than in the finished product. It is important for the participants to 'find a voice'. What they say with their voice is less important (p. 194).

ICE Director Lena Nahlous acknowledges that some ICE events need to be held in the city in order to attract an audience, giving the example of a refugee writers' event which formed part of the Sydney Writers Festival in the mid 2000s. Nahlous says the audience, largely Anglo Australians, would probably not have travelled to Parramatta for the event (Nahlous 2011).

Arguably then, for Western Sydney to be genuinely accepted as a culturally vibrant region, it needs to move on from relying on CCD projects for cultural production - or at least, the relationship between community development and cultural production needs deeper consideration. Organisations like ICE have reached a level of maturity to enable such considerations. Recently ICE reframed its work in a binary structure, setting its Cultural Development Program apart from its Creative Enterprise Program. The latter focuses more heavily on professional development, employment and creative and entrepreneurial leadership (ICE 2009) - a framework distinct from one of community empowerment and redressing disadvantage. Another notable shift is the disappearance of the term CCD from official ICE rhetoric, mirroring the changing discourse in government and other circles (for example, at the Australia Council, CCD is now known as Community Partnerships).

Tanja Dreher (forthcoming) analyses two distinct logics in ICE projects, which she terms 'affirmation' and 'competition'. The former comprise the traditional CCD projects, engaging disadvantaged populations with the goal of providing access to resources as opposed to aiming for professional quality outputs. 
The latter category is structured around competitive processes (e.g. to win a film-making scholarship), professional development and mentoring.

Such projects are helping Western Sydney arts shake off the perception that local cultural activity is organised for welfare rather than artistic purposes. However, to the extent that hip hop or digital storytelling workshops are still often framed in terms of 'keeping kids off the streets' (in spite of the best efforts of organisations like ICE), Western Sydney cultural production may continue to be viewed within a welfare model that measures success in terms of participation levels and the development of individuals rather than innovative end products.

The question remains: is a welfare approach a necessary stepping stone, an affirmative action program for a historically marginalised region? Alternatively, does the CCD approach monopolise cultural production to the extent that different practices fail to be developed? Does it reinforce the region's marginalised status by presenting its artistic community as always in 'development' and never truly 'accomplished'?

Organisations such as ICE may well be starting to blur the boundaries between traditional community development and a more entrepreneurial approach to facilitating artistic excellence and innovation. In this sense also, they are pioneers in the 'reinvention' of CCD practice. In the future, this transformed CCD may become more detached from associations with redressing disadvantage and empowering communities. This may leave a gap in the provision of services to communities that remain disadvantaged, a significant question that is not addressed here. However, it may also lead to a diversification in the types of cultural production emerging from Western Sydney, which in time may convince more and more Australians to accept the image of the region as a new and exciting centre of Australian creativity.

What does all this mean for how we evaluate arts programs? This article has argued that capturing the social impact of community arts programs requires a development of evaluation techniques, beyond the quantitative. In attempting to document the social impact of an organisation like ICE, including the cumulative 'ripple effects' of its programs throughout Western Sydney and beyond, this article has deployed several distinct research methods, both qualitative and quantitative. Unfortunately, community-based organisations rarely have the time or funding to carry out this kind of holistic research. However, with the growing consensus on the urgent need to expand our methods for evaluating the various impacts of community programs, it is hoped funders and community practitioners will increasingly be in a position to integrate these kinds of research methods into the core of their daily practice. 


\section{REFERENCES}

Australia Council 2006, 'Community partnerships scoping study: Creative communities', Australia Council for the Arts, Sydney.

Australia Council 2009, KP11: Producing communities, Australia Council for the Arts, Sydney.

Belfiore, E 2004, 'Auditing culture: The subsidized cultural sector in the New Public Management', International Journal of Cultural Policy, vol. 10, no. 2, pp. $183-20$.

Brook, S 2008, 'The art of government: Khoa Do's The Finished People and the policy reform of community cultural development', Studies in Australasian Cinema, vol. 2, no. 3, pp. 177-93.

Brown, P 2008, 'Knowledge, power and cultural policy: Social understanding through community cultural development', in L Andersen \& K Oakley (eds), Making meaning, making money: Directions for the arts and cultural industries in the creative age, Cambridge Scholars Publishing, Newcastle upon Tyne, pp. 227-42.

Burchell, D 2003, Western horizon: Sydney's heartland and the future of Australian politics, Scribe, Melbourne.

Burgess, J 2006, 'Hearing ordinary voices: Cultural studies, vernacular creativity and digital storytelling', Continuum: Journal of Media and Cultural Studies, vol. 20, no. 2, pp. 201-14.

Butcher, M 2003, 'Revisioning Sydney', Space and Culture, vol. 6, no. 2, pp. 187- 94 .

Collins, J \& Poynting, S 2000, The other Sydney: Communities, identities and inequalities in Western Sydney, Common Ground Publishing, Melbourne.

Couldry, N 2008, 'Mediatization or mediation? Alternative

understandings of the emergent space of digital storytelling', New Media \& Society, vol. 10, no. 3, pp. 373-91.

Cultural Development Network (CDN) 2010, 'Arts indicators for local government: Valuing, planning for and measuring the contribution of the arts in local government in Australia, Part 2a: A framework for arts indicators for local government', viewed 29 May 2012, http://www. culturaldevelopment.net.au/downloads/ArtsIndicators-PartB1.pdf.

Dennis, A 1999, 'A laboratory to test the city's sanity', The Sydney Morning Herald, 6 March, p. 3.

Guetzkow, J 2002, 'How the arts impact communities: An introduction to the literature on arts impact studies', paper presented to the 'Taking the Measure of Culture' Conference, Princeton University, 7-8 June.

Hartley, J \& McWilliam, K 2009, 'Computational power meets human contact', in J Hartley \& K McWilliam (eds), Story circle: Digital storytelling around the world, Blackwell, Malden, MA. pp. 3-15.

Hawkes, J 2001, The fourth pillar of sustainability, Cultural Development Network, Melbourne.

Hawkins, G 1993, From Nimbin to Mardi Gras: Constructing community arts, Allen \& Unwin, Sydney.

ICE (Information and Cultural Exchange) 2011, 'About ICE', viewed 3 June 2011, http://ice.org.au/about/intro.

ICE (Information and Cultural Exchange) 2009, 26th Annual Report, Information and Cultural Exchange, Sydney. 
Lally, E 2004, 'A strategy for the arts in Western Sydney - An evaluation', Centre for Cultural Research, University of Western Sydney, Sydney.

Lalor, P 1999, 'A vision splendid', Daily Telegraph, 6 March, p. 44.

Matarasso, F 1997, Use or ornament? The social impact of participation in the arts, Comedia, Stroud.

McDonald, J 2005, 'Westerly directions', Sydney Morning Herald, Spectrum, 23 July, pp. 28-9.

McEwen, C 2008, Investing in play: Expectations, dependencies and power in Australian practices of community cultural development, $\mathrm{PhD}$ thesis, University of Sydney.

Mills, D 2008, 'Citizen values and the arts: New language for Australian cultural policy', in L Andersen \& K Oakley (eds), Making meaning, making money: Directions for the arts and cultural industries in the creative age, Cambridge Scholars Publishing, Newcastle upon Tyne, pp. 205-26.

NSW Ministry for the Arts \& NSW Government's Office of Western Sydney 1999, 'A strategy for the arts in Western Sydney', Sydney, viewed 1 October 2010, www.arts.nsw.gov.au/index.php/news-and-publications/ publications/western-sydney-arts-strategy/

NSW Ministry for the Arts 2006, The arts in Western Sydney: 2006 progress report on the NSW Ministry for the Arts Western Sydney arts strategy, Sydney, viewed 1 October 2010, http://www.arts.nsw.gov.au/index.php/news-andpublications/publications/western-sydney-arts-strategy-2006-progressreport/

Opdycke, S, Jackson, M-R, Herranz, J \& Shigekawa, J 2003, 'Cultural vitality: Arts, culture and the social health of the nation', report to the 'Grantmakers in the Arts' Conference, Seattle, October 19-22.

Office of Western Sydney (OWS) 2011, 'Western Sydney', viewed 7 November 2011, http://www.westernsydney.nsw.gov.au/.

Parramatta Advertiser 2011, Distribution, 9 November, p. 2, viewed 10 November 2011, digitaledition.parramattaadvertiser.com.au/\#folio=3.

Pitt, H 2010, 'The zest in the west: Sydney's sizzling centre', Sydney Morning Herald, 21 August, viewed 11 November 2011, http://www.smh.com.au/ entertainment/restaurants-and-bars/the-zest-in-the-west-sydneys-sizzlingcentre-20100820-138yu.html

Productivity Commission 2010, 'Contribution of the not-for-profit sector', research report, Productivity Commission, Canberra.

Ramsey White, T \& Rentschler, R 2005, 'Toward a new understanding of the social impact of the arts', paper presented at the AIMAC 2005: Proceedings of the 8th International Conference on Arts and Cultural Management, Montreal.

Rose, G 1997, 'Performing inoperative community: The space and the resistance of some community arts projects', in S Pile \& M Keith (eds), Geographies of resistance, Routledge, London, pp. 184-202.

Walker, C, Fleming, C \& Sherwood, K 2003, Arts participation: Steps to stronger cultural and community life, The Urban Institute, Washington DC.

Williams, D 1996, 'The social impact of arts programs. How the arts measure up: Australian research into social impact', Comedia Working Paper 8, Stroud. 
Yin, R 1989, Case study research: Design and methods, Sage Publications, Newbury Park, CA.

\section{Interviews}

Tim Carroll, Bankstown Youth Development Service (interviewed 2010)

Alissar Chidiac, Casula Powerhouse (interviewed 2010)

Claudia Chidiac, Powerhouse Youth Theatre (interviewed 2010)

Lina Kastoumis, Urban Theatre Projects (interviewed 2010)

Elaine Lally, University of Technology, Sydney (interviewed 2010)

Lena Nahlous, Information and Cultural Exchange (interviewed 2011)

Frank Panucci, Australia Council for the Arts (interviewed 2010)

Kim Spinks, Arts NSW (interviewed 2011)

Maria Tran, Information and Cultural Exchange (interviewed 2011) 